\title{
Approaches and possibilities for reducing residual stresses in induction brazed cemented carbide/steel joints
}

\author{
K. Bobzin ${ }^{1} \cdot$ M. Öte ${ }^{1} \cdot$ J. Hebing ${ }^{1}$ (i) \\ Received: 18 October 2019 / Accepted: 24 May 2020 / Published online: 6 June 2020 \\ (C) The Author(s) 2020
}

\begin{abstract}
Induction brazing is widespread in many industries due to its ability for local contactless heating as well as its high heating rates and the associated short cycle times. As a result of these advantages, this brazing process is particularly widespread in the tool industry for mass products made of cemented carbide/steel, for example, in saw blades or milling tools. The state of the art is the use of one or more pyrometers for measuring the surface temperature of the component. However, the measurement can be significantly falsified due to oxidation of the component surface and flux residues or due to the evaporation of the flux. Due to the resulting control deviations and the lack of information about the temperature inside the brazing gap, critical residual stresses can be induced in the joint, which can lead to premature failure of the component. An approach is presented that uses distance and force measurements to monitor the condition of the filler metal in the brazing gap. By using these sensors, the point in time at which the entire filler metal has liquefied can be determined. In this way, overheating of the component can be avoided and the holding time and thus also the residual stresses can be reduced to a minimum. Furthermore, numerical calculations are presented, which compare the resulting residual stresses with conventional brazing foils as well as with brazing foils with a pure copper intermediate layer. In addition, the influence of the thickness of the filler metal was examined. The results show that the choice of the right brazing foil architecture and the thickness of the brazing foil have a significant influence on the residual stresses.
\end{abstract}

Keywords Induction brazing $\cdot$ Residual stresses $\cdot$ Cemented carbide steel $\cdot$ Process control

\section{Introduction}

Cemented carbides are sintered metal matrix composites which consist of a fine-grained hardness carrier, usually tungsten (WC), titanium (TiC) or tantalum carbide $(\mathrm{TaC})$, and a metallic matrix. Cobalt $(\mathrm{Co})$ and nickel $(\mathrm{Ni})$ and iron $(\mathrm{Fe})$ or alloys of these elements are usually used as the matrix material [1]. Due to the high content of hard materials of up to $\mathrm{m}_{\mathrm{c}}>90 \mathrm{wt} . \%$, these materials have a very high hardness and wear resistance. For this reason, cemented carbides have become established as an indispensable class of materials in many industries [2]. Cemented carbides are an appealing material, not only for metal and wood cutting (Fig. 1A, B), but also for the mechanical

Recommended for publication by Commission XVII - Brazing, Soldering and Diffusion Bonding

J. Hebing

hebing@iot.rwth-aachen.de

1 Surface Engineering Institute, RWTH-Aachen University, 52072 Aachen, Germany removal of mineral substances (Fig. 1C), for example, for the extraction of raw materials and in the construction sector [1].

Owing to their high content of hard materials, cemented carbides not only have high hardness, but also exhibit very brittle material behaviour, which presents major challenges, in particular when joining cemented carbides with metallic materials (Fig. 1). Hence, the induced internal stresses represent a major problem in joining processes, such as welding or brazing cemented carbides with a metallic carrier material, such as steel. However, due to the overall lower thermal load, brazing could be established as an economic joining method for many carbide/steel joints despite the internal stresses remaining a major challenge in brazing. Due to the different thermal expansion coefficients of the cemented carbide and the steel, inhomogeneous stress states are induced in the component. The induced tensile stresses in the cemented carbide can assume critical values, leading to spontaneous failure of the cemented carbide during the joining process, within the cooling phase or even during use $[3,4]$. In the significantly tougher steel, the induced residual stress is usually not a problem. 

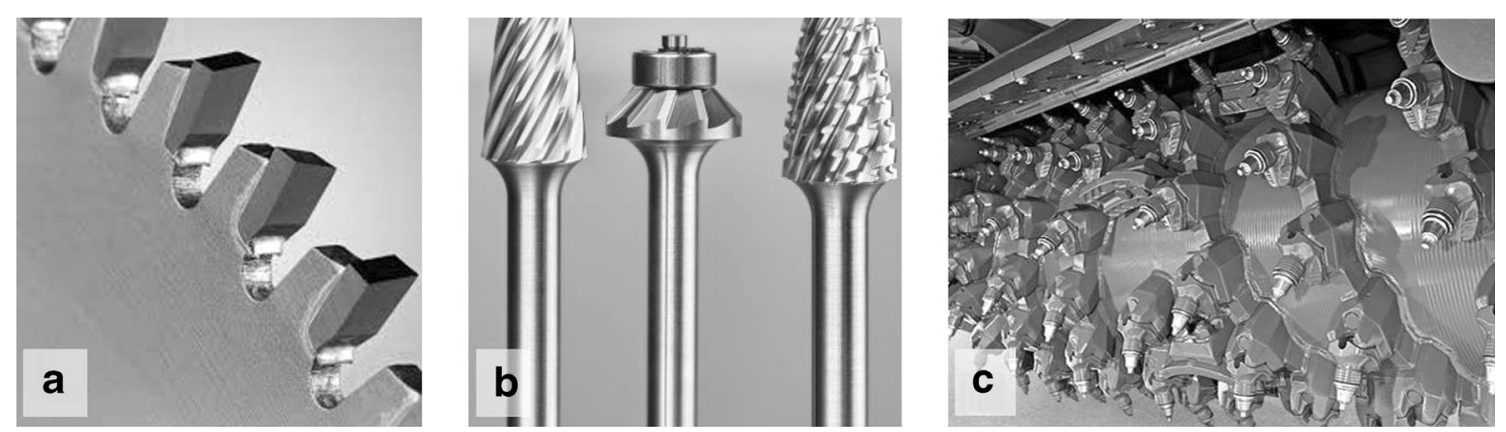

Fig. 1 Examples of cemented carbide steel joints such as saw blades (A) [5], milling tools (B) [6] and cold milling machines for road construction (C) [7]

Most brazing techniques such as torch brazing, infrared brazing, vacuum furnace brazing, or induction brazing can be used to braze cemented carbide/steel joints $[4,8-10]$. Due to the high possible heating rates of $\dot{T}>200 \mathrm{~K} / \mathrm{s}$, very short cycle times, and good automatability, induction brazing has become established for frequently repeated component geometries, e.g. for brazing saw blades and similar tools. In induction brazing, a coil through which a high-frequency alternating current flows is used as the heating device. The alternating current generates a high-frequency alternating electromagnetic field, which induces an eddy current on the surface of the component. The current density J, and thus the induced power or heat, decreases from the component surface to the core. This effect, also known as the "skin effect", requires deeper heating by heat conduction. For this reason, the dwell time at brazing temperature is essential to produce highquality joints [11]. The temperature detection at the brazing gap is, according to the current state of the art, only superficially possible by means of contactless pyrometer measurements.

The actual temperature or state of the filler metal in the core of the brazing gap is unknown. Since pyrometers calculate the surface temperature based on the emitted infrared radiation, the measurements are often falsified by vapours (flux) or by oxidation of the component. Due to this error-prone temperature control, there are often temperature fluctuations, which lead to wetting errors with the filler metal at too low temperatures and thus to loss of strength and quality. If the temperatures are too high, higher residual stresses are induced in the joint. In addition, at high temperatures, $\eta$-carbides like $\mathrm{Co}_{6} \mathrm{~W}_{6} \mathrm{C}, \mathrm{Co}_{3} \mathrm{~W}_{3} \mathrm{C}$, and $\mathrm{Co}_{2} \mathrm{~W}_{4} \mathrm{C}$ [12] are formed, which leads to further embrittlement of the joint [13].

Based on these problems, it was investigated how the residual stresses can be reduced without impairing the economic efficiency of the process. It is assumed that the process times or cycle times for producing a brazed joint, the material used (substrate, filler metal, flux), and the reject rate are decisive for the economy of these brazing process. In the first step, the foundations for an improved monitoring concept were developed, which can improve the process control and thereby reduce residual stresses as well as wetting errors and the formation of brittle phases in the future. In the second step, numerical calculations were carried out in order to investigate and understand the effect of different brazing foils thicknesses and types of foils on the residual stress state in cemented carbide/steel joints.

\section{Advanced control system}

A reliable detection of the temperature or of the state of the filler metal in the core of the brazing gap is essential to reduce the residual stresses after the induction brazing process to a minimum. A new approach is to monitor the geometry and changes in the force acting on the part during the brazing process. Figure 2 schematically shows an induction brazing process of a cylindrical sample. The basic idea is, upon reaching the melting temperature in the complete brazing gap, it leads to sagging of the upper substrate as a result of the liquefaction of the filler metal. This sagging can either be measured as a change in the sample height or as a force change by means of displacement and force sensors respectively. The functionality of the approach has already been demonstrated on cemented carbide/steel samples by initial displacement and force measurements in induction brazing tests and using a dilatometer [14]. The current work focuses on the applicability of these approaches to layered brazing foils with thin filler metal thicknesses as well as the verification of the correlation of the core temperature with the sagging of the upper substrate.

\subsection{Experimental setup}

Figures 3 and 4 show the test rig with a sample during induction brazing. The investigations were carried out with an induction brazing system of the type TTH5 of the company "iew Induktive Erwärmungsanlagen GmbH" (Gumpoldskirchen, Austria). The system has a maximum power output of $P=$ $5 \mathrm{~kW}$ and works in this configuration with a frequency of approx. $f=210 \mathrm{kHz}$. The temperature control is realized by a quotient pyrometer, which has a measuring range of $250^{\circ} \mathrm{C}<$ $T<1300{ }^{\circ} \mathrm{C}$. An additional second pyrometer is used for 


\begin{tabular}{|l|l|}
\hline $\begin{array}{l}\text { Temperature: } \mathrm{T}=\mathrm{T}_{\mathrm{R}} \\
\text { Brazing foil between } \\
\text { cemented carbide and steel }\end{array}$ & - Temperature: $\mathrm{T}_{\mathrm{R}}<\mathrm{T}<\mathrm{T}_{\text {Liquidus }}$ \\
\hline
\end{tabular}

Fig. 2 Schematic representation of the sagging of the upper substrate during the induction brazing process [14]

process monitoring and comparison with the force and displacement sensor data. The reproducible position of the samples in the induction field and the constant position of the sensors were ensured by a purpose-made device (Fig. 3).

In addition to the positioning of the sensors and the samples, the test rig can also apply a contact pressure by adding weights, which transmit the force via a contact pin on the sample top (Fig. 4). To measure the force changes, the piezoelectric force sensor $208 \mathrm{C} 01$ of the company PCB Piezotronics (Depew, USA) was installed in the brass base. The changes in the sample height were measured by means of a laser displacement sensor of the type ILD1750-10 from Micro-Epsilon (Ortenburg, Germany). The sensor was shielded from the induction field by a steel plate and mounted above the test rig. The displacement sensor does not directly measure the height of the sample, but the change in position of the weight. The digitization and processing of the measured data were realized by a measuring amplifier of the type

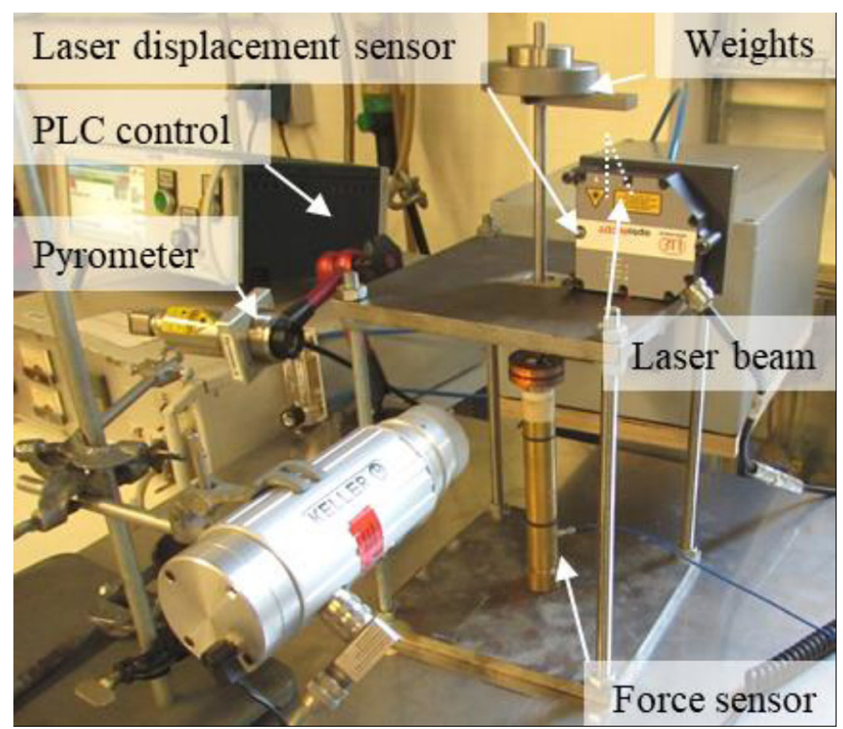

Fig. 3 Test rig for induction brazing with preloading and measuring devices [14]
Quantum X 840B of the company "Hottinger Baldwin Messtechnik GmbH". With this configuration of sensors and measuring amplifiers, the sensor resolution is $\Delta x \approx 0.15 \mu \mathrm{m}$ for the laser displacement sensor and a resolution of $\Delta F \approx$ $0.016 \mathrm{mN}$ for the force sensor.

The sample geometry consisted of two cylindrical 1.7225 steel substrates, each with a diameter of $d=16 \mathrm{~mm}$ and a height of $h=15 \mathrm{~mm}$. The surfaces to be joined were ground with 400-grit sandpaper and cleaned with ethanol. Different brazing foils (Table 1) were placed between the substrates. In addition, a FH12 flux was used. The tests were limited to steel substrates because they are easier to prepare and to dissect. Furthermore, previous studies showed that no differences in sagging between cemented carbide/steel and steel/steel samples are to be expected [14].

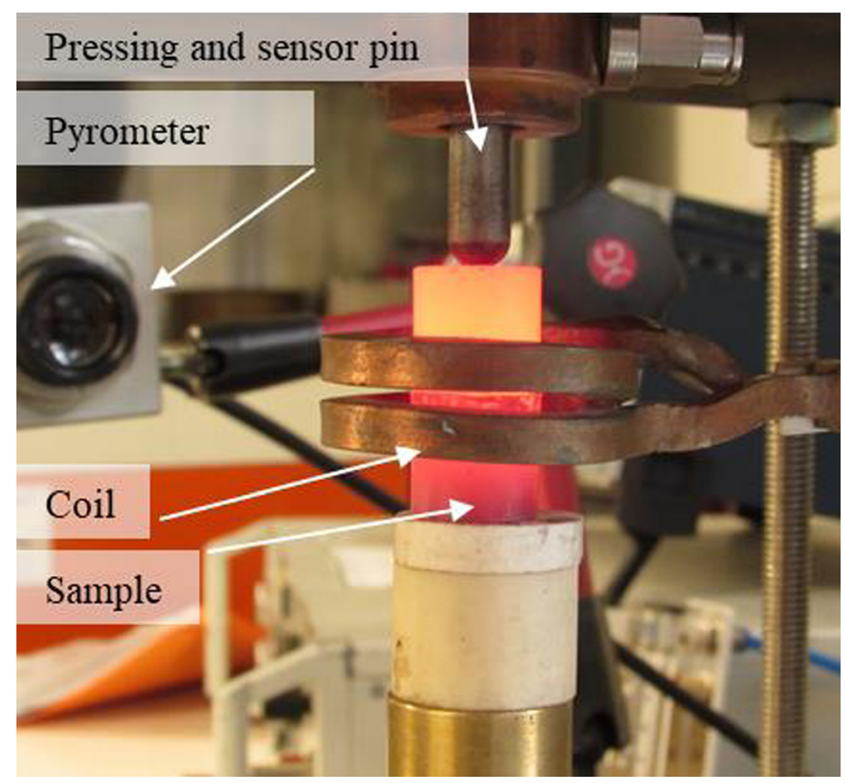

Fig. 4 Brazing process in the test rig [14] 
Table 1 Technical data for the used brazing foils

\begin{tabular}{|c|c|c|c|c|c|c|c|c|}
\hline \multirow[t]{2}{*}{ Filler metal } & \multicolumn{5}{|c|}{ Composition (wt.\%) } & \multirow{2}{*}{$\begin{array}{l}\text { Melting interval } \\
\left({ }^{\circ} \mathrm{C}\right)\end{array}$} & \multirow{2}{*}{$\begin{array}{l}\text { Thickness } \\
(\mathrm{mm})\end{array}$} & \multirow[t]{2}{*}{ Source } \\
\hline & $\mathrm{Ag}$ & $\mathrm{Cu}$ & $\mathrm{Zn}$ & $\mathrm{Mn}$ & $\mathrm{Ni}$ & & & \\
\hline Ag 449 (Bag-22) & 49 & 16 & 23 & 7.5 & 4.5 & $680<T<705$ & $0.1 / 0.2$ & {$[15]$} \\
\hline $\mathrm{Ag} 49 / \mathrm{Cu}^{*}$ & 49 & 27.5 & 20.5 & 2.5 & 0.5 & $670<T<690$ & $0.2 / 0.3 / 0.4$ & {$[16]$} \\
\hline Ag 272 (Bag-8) & 72 & 28 & - & - & - & $T=780$ & 0.1 & {$[17]$} \\
\hline
\end{tabular}

*Copper interlayer, thickness $t_{\mathrm{Cu}}=1 / 2 t_{\text {foil }}$

\subsection{Measurements in the induction brazing process}

Figure 5 shows the results of temperature, displacement, and force measurements during the induction brazing process. Both processes have reached the set temperature of $T=$ $730{ }^{\circ} \mathrm{C}$. The measurements show a significant oscillation in the heating phase in the region I. This was caused by the evaporation and melting of the flux. Approximately $3 \mathrm{~s}$ after reaching the target temperature at the surface, the force signal shows a temporary release with a subsequent load in region II. The point in time of the force peak correlates with the decrease of the sample height in the displacement signal. The peaks in the force and displacement signal are attributed to the liquefaction of the filler metal.

The time offset can be attributed to the skin effect and the associated surface heating. The heat has to reach the core of the sample via thermal conduction. That is the reason why the brazing foil in the core area of the brazing gap melts with a few seconds delay. The comparison of the results with the conventional brazing foil (A) and with those of the brazing foil with the $\mathrm{Cu}$ interlayer (B) shows that the sagging distance is comparable. However, in the force signal of $\mathrm{B}$ a smaller, but a double sagging can be detected. The cause is the separate melting of the upper and lower filler metal layer of the brazing foil. Compared with A, the double sagging also leads to an apparent slowed sagging in B.

In the next step, the accuracy and performance of the monitoring methodology were examined. The eutectic filler metal alloy Ag 272 was chosen for this purpose. Furthermore, the upper substrate of the sample setup was provided with a core hole of $d_{\varnothing}=1.6 \mathrm{~mm}$ and a depth of about $d_{\text {depth }}=13.5 \mathrm{~mm}$. Through the bore hole, the core temperature could be determined approx. $d=1.5 \mathrm{~mm}$ above the brazing plane by means of a thermocouple, which was shielded by a steel pipe against the electromagnetic alternating field. By combining core temperature measurement and a filler metal with a defined melting

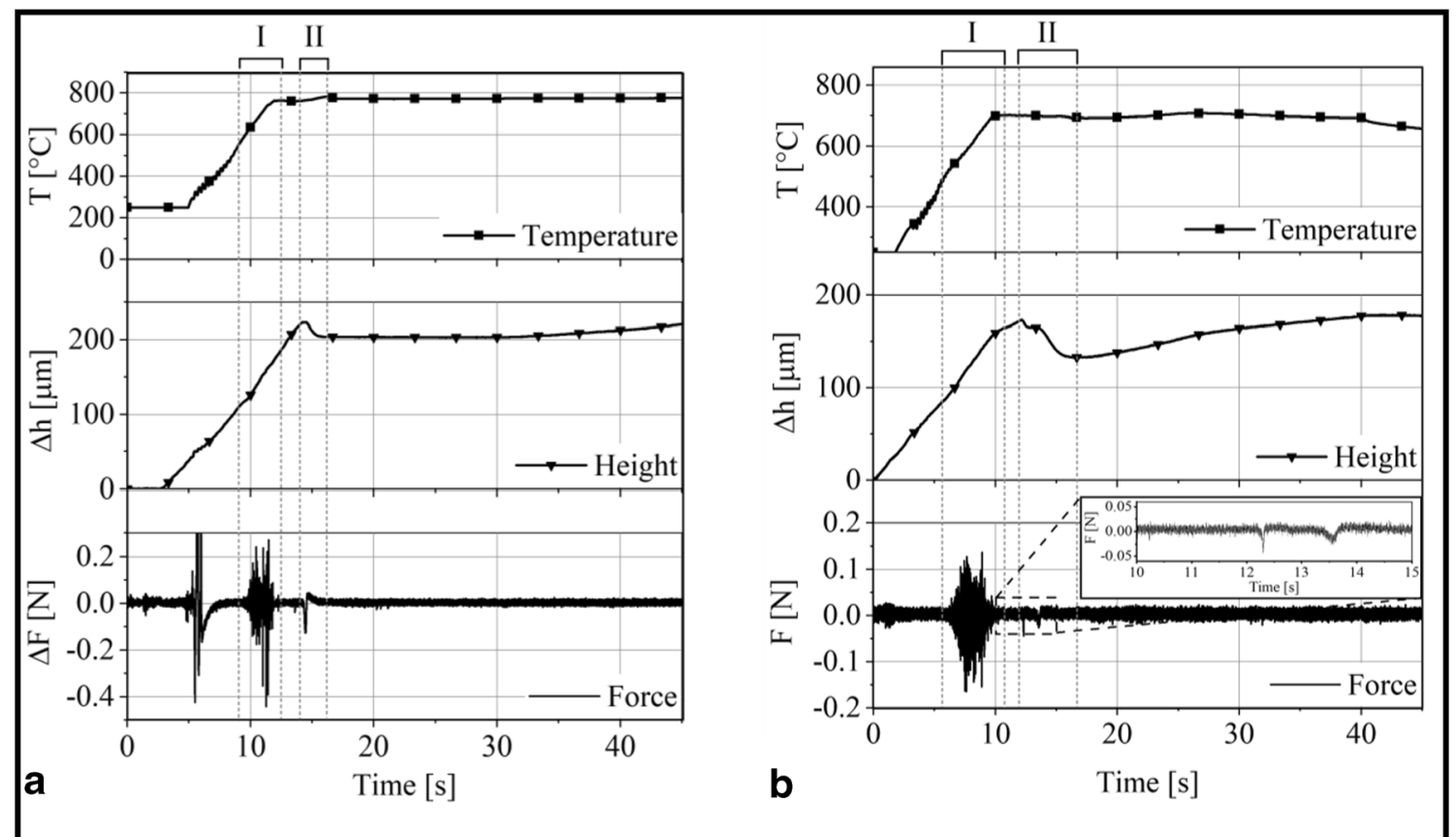

Fig. 5 Results of the temperature (pyrometer measurement), displacement, and force measurement during the induction brazing process using Ag 449- (A) and Ag 49/Cu-brazing foil (B), $t_{\text {foil }}=$
$0.2 \mathrm{~mm}$, brazing temperature $T_{\text {set }}=730{ }^{\circ} \mathrm{C}$, dwell time $t=30 \mathrm{~s}$, heating rate $\dot{T}=60 \mathrm{~K} / \mathrm{s}$ 
point, it was possible to investigate whether sagging only takes place when the melting temperature reaches the core of the brazing gap.

Figure 6 shows the results of a test with an eutectic silvercopper brazing foil. As in the previous investigations, evaporation of the flux (region I) as well as sagging of the upper substrate (region II) during the brazing process can be detected. The results show that the core temperature lags due to the skin effect and the onset of heat conduction of the surface temperature and converges to the surface temperature. Upon reaching the melting point of the $\mathrm{Ag} 272$ brazing foil of $T=$ $780{ }^{\circ} \mathrm{C}$, there is a sagging which can be observed in the force and in the displacement signal. Thus, it could be proven that the sagging allows precise statements about the filler metal state in the core of the brazing gap and indirectly also allows statements to be made about the temperature.

The results show that the approach also works for brazing foils with a $\mathrm{Cu}$ intermediate layer, which only have thin filler metal layers. It was also shown that the sagging of the upper substrate corresponds to the melting temperature reached in the core of the brazing gap. The measurements show a high reproducibility. Uncertainties arise, in particular, from the use of flux, which is particularly evident when using the force sensor. In the case of very fast brazing processes with high heating rates, there is a risk that the sagging will take place at the same time as the flux reaction and therefore cannot be

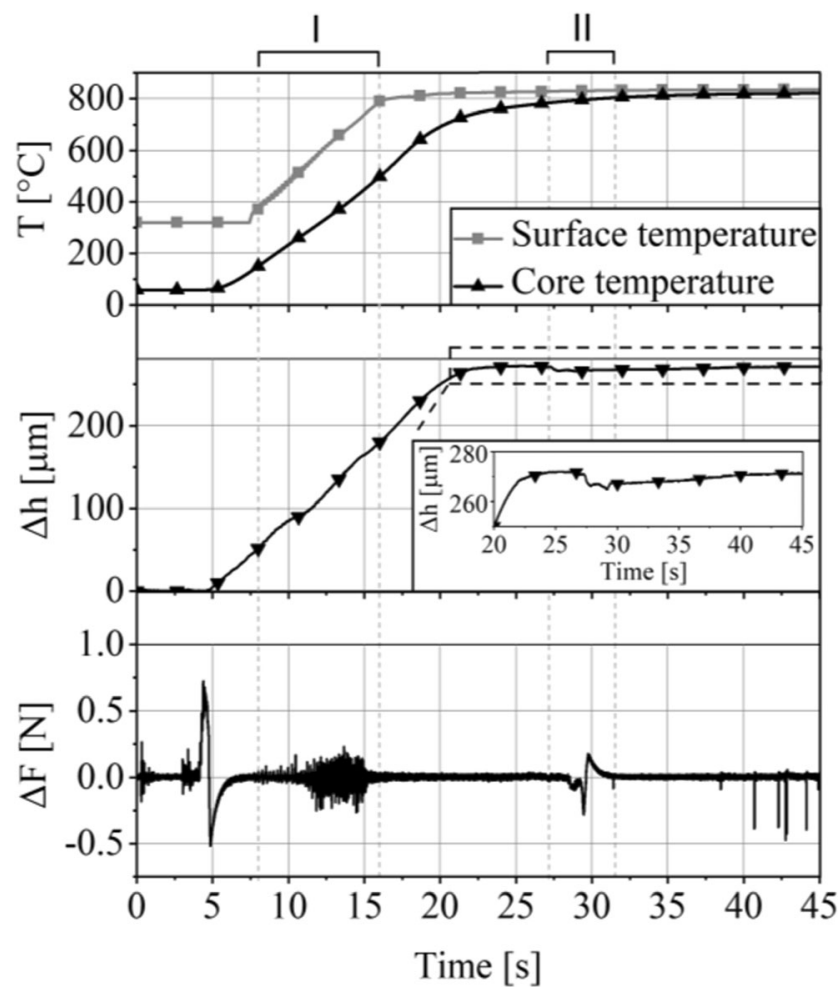

Fig. 6 Results of the temperature (pyrometer in grey, thermocouple in black), displacement and force measurement in the induction brazing process using an eutectic Ag 272-brazing foil, $t_{\text {foil }}=0.2 \mathrm{~mm}$, brazing temperature $T_{\text {set }}=800{ }^{\circ} \mathrm{C}$, dwell time $t=30 \mathrm{~s}$, heating rate $\dot{T}=60 \mathrm{~K} / \mathrm{s}$ detected. During the measurements, it was also noticed that the force sensor is also sensitive to environmental influences. In contrast, the measurements using the laser displacement sensor are much more stable. Effects of the evaporation of the flux or environmental influences are absorbed only weakly and can be damped further using an appropriate low-pass filter.

\section{Influence of the brazing foil on the residual stress state}

The residual stresses that occur when brazing cemented carbide and steel have been researched for a long time [18-20]. The measurement of the internal stress is particularly difficult in the deeper areas of the brazing joint. In addition, an understanding of the residual stresses is necessary to effectively reduce them. For this reason, the focus is on the numerical calculation of the residual stresses. Many of the previous studies deal with a concrete model, neglecting geometry dependencies. In addition, the calculation model is simplified in most studies by neglecting the temperature-dependent mechanical properties of the materials. As part of this work, the mechanical properties depending on the temperature are used to calculate the residual stresses. In addition, the residual stresses should be considered depending on the geometry (foil architecture, foil thickness).

\subsection{Calculation model}

The FEM software ANSYS 19.1 was used for the analysis of residual stresses in the dependency of different brazing foil thicknesses and brazing foil types. The developed calculation model was based on three-dimensional thermal-mechanical models of different joining samples. The model calculates the resulting residual stresses induced in the component during the cooling process after the joining.

The following boundary conditions, simplifications, and assumptions were made in the modelling:

- Starting point: homogeneous temperature distribution of $T_{\text {Start }}=690^{\circ} \mathrm{C}$

- Homogeneous and linear cooling to $T_{\mathrm{R}}=20{ }^{\circ} \mathrm{C}$ (end point)

- Constant chemical composition of the filler metal and the substrates

- No phase transformation $(\gamma-\alpha)$

- Time invariant plastic stress relaxation (no relaxation)

- Isotropic physical and mechanical properties of the substrates and filler metals

The bases for the numerical calculations of the residual stresses are the results of dilatometer measurements and flow 
curves. The following materials were used for the measurements:

Brazing foil and intermediate layer:

- Brazing foil: Ag 449 (ISO 17672)/AG 502 (AWS)

- Pure copper

Substrates:

- Tempered steel: $1.7225 /$ AISI 4140

- Fine-grained cemented carbide with $m_{\mathrm{Co}}=8 \mathrm{wt} . \%$ cobalt

For the dilatometer measurements, a SETSYS Evolution system (Caluire-et-Cuire, France) was used. The results of the dilatometer measurements are shown in Fig. 7. It can be recognized that the cemented carbide and the steel have significantly different thermal expansion coefficients. In addition, a significant change in the thermal expansion coefficient of the steel in the temperature range between $750{ }^{\circ} \mathrm{C}<T<$ $800{ }^{\circ} \mathrm{C}$ can be seen. This is the austenitization of the steel, whereby the density of the material increases, and thus the volume decreases, during the $\alpha-\gamma$ conversion. Since the working temperature of the used brazing foils is just below the austenitization, this need not be considered further for the model. When looking at the measurements for the brazing foil and pure copper, it is also noticeable that the thermal expansion coefficients are higher than those of the steel and the cemented carbide substrate. Due to the significantly higher ductility and the low softening temperature of the filler material and the copper interlayer, these are only negligibly involved in the induction of residual stresses. Due to the high ductility, stresses can even be reduced by plastic deformation.

In order to make the model as accurate as possible, flow curves for different temperatures [21-23] were added to the model in addition to the dilatometer measurements. By including the flow curves of the different materials, in addition to the

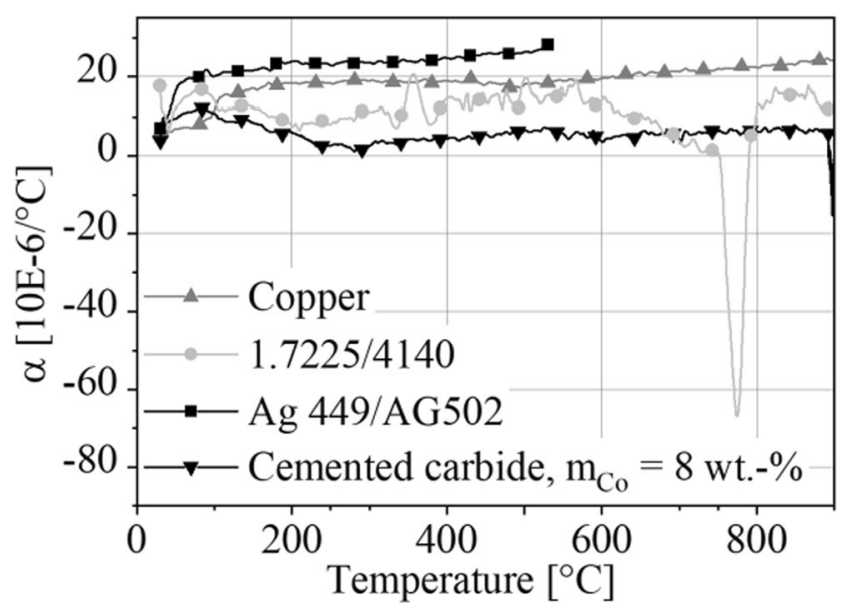

Fig. 7 Results from dilatometer measurements of substrates, the brazing foil $\mathrm{Ag} 449$ and pure copper elastic deformations, the plastic change and concomitantly a plastic degradation of the residual stresses should be simulated. The flow curves in Figs. 8, 9, 10, and 11 were created as part of previous work and were recorded using pressure tests in accordance with DIN 50106 [24]. An MTS universal tensile compression testing machine with a heating chamber was used for the pressure tests. The compression tests were carried out on cylindrical samples with a diameter of $d=5 \mathrm{~mm}$ and a height of $h=8 \mathrm{~mm}$. The properties of the substrates, in particular of the steel, were modelled on the brazing processes by a previous heat treatment.

The calculation model was a three-dimensional sample geometry consisting of a cylindrical steel substrate and a cylindrical cemented carbide substrate, both with a diameter of $d=$ $16 \mathrm{~mm}$ and a height of $h=15 \mathrm{~mm}$ (Fig. $12 \mathrm{~A}$ ). The circular geometry was chosen to provide a simplified symmetric residual stress distribution without edge effects. Between the substrates, different types of brazing foils were assumed, which were firmly bonded to the substrates. Conventional brazing foils of the alloy Ag 449 or AG 503 as well as brazing foils of this alloy in combination with a $\mathrm{Cu}$ intermediate layer were assumed. The thicknesses of the brazing foils are based on dimensions which are typically used in the industry. Consequently, thicknesses of $d_{\mathrm{Ag} 449}=0.1 \mathrm{~mm}, 0.15 \mathrm{~mm}$, and $0.2 \mathrm{~mm}$ were assumed for the conventional brazing foils. In the case of the brazing foils, which contained a $\mathrm{Cu}$-interlayer, thicknesses of $d_{+\mathrm{Cu}}=0.2 \mathrm{~mm}, 0.3 \mathrm{~mm}$, and $0.4 \mathrm{~mm}$ were assumed. The $\mathrm{Cu}$-interlayer accounts for half of the total thickness of the brazing foil.

The different mechanical properties of the material can be seen from the flow curves. The filler metal and the copper show a ductile material behaviour. In contrast, the cemented carbide in particular shows brittle material behaviour even at $T=500{ }^{\circ} \mathrm{C}$. For the calculations, it was assumed that cemented carbide has a purely elastic behaviour. An elastic-plastic behaviour was assumed for the steel and the filler metal as well as for the $\mathrm{Cu}$ intermediate layer.

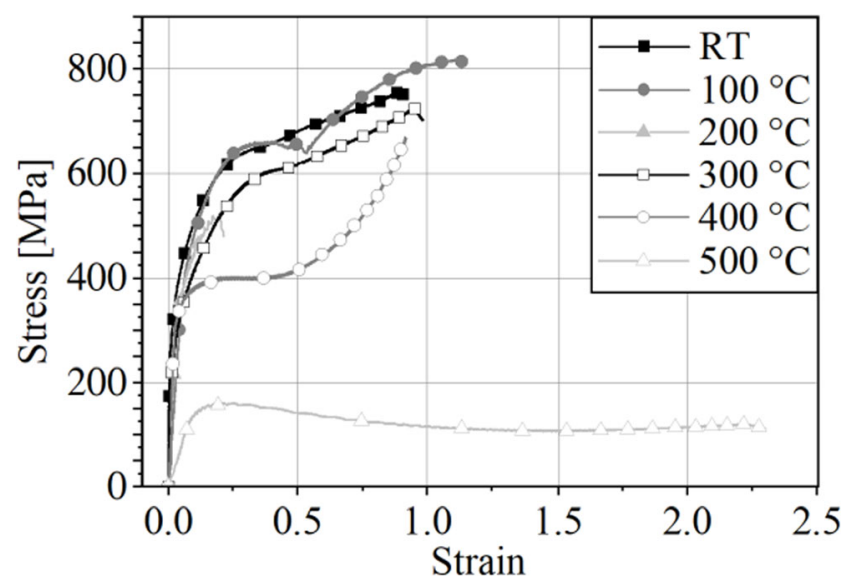

Fig. 8 Flow curves of the filler metal Ag 449/AG 502 at different temperatures [21, 22] 


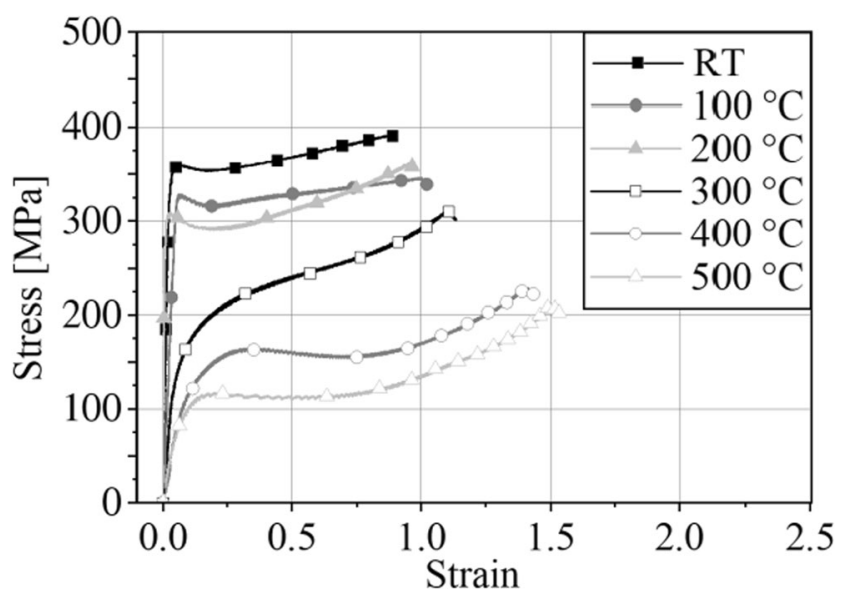

Fig. 9 Flow curves of copper at different temperatures [21, 22]

\subsection{Calculated residual stresses}

Figure 12 shows the three-dimensional calculation model (A) and results for two different sample setups $(\mathrm{B}, \mathrm{C})$. The finite element grid is shown in Fig. 12A. With the selected settings, there were approx. $n=46,000$ elements, with slight deviations depending on the structure of the filler metal. The presented results were calculated according to "Von Mises" or the maximum distortion energy criterion. The results show that in both sample configurations, a residual stress concentration $\left(\sigma_{\mathrm{Max}}\right)$ occurs in the outer edge region at the interface between the filler metal and the cemented carbide. In a direct comparison of the results, it can be seen that the use of brazing foils with $\mathrm{Cu}$ interlayer leads to a reduction in the residual stresses in the cemented carbide. The cause of this residual stress reduction is an increased degree of plastic deformation or a plastic residual stress reduction in the filler metal, which is made possible by the pure copper layer. In addition, the maximum residual stress in the sample setup with the conventional brazing foil is located in the cemented carbide. In contrast, the maximum residual stress of the sample setup containing a $\mathrm{Cu}$-interlayer is located in the filler metal between the cemented carbides and the $\mathrm{Cu}$-interlayer.

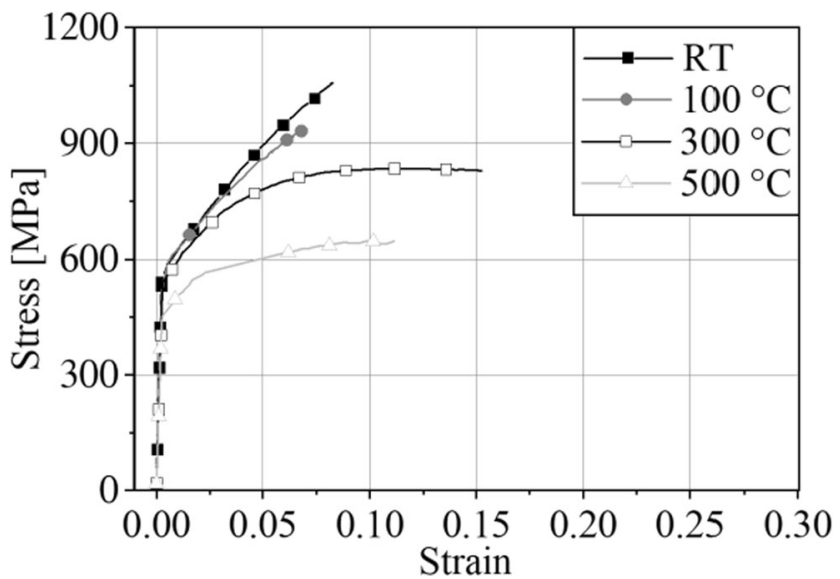

Fig. 10 Flow curves of the steel $1.7225 / 4140$ at different temperatures $[21,22]$

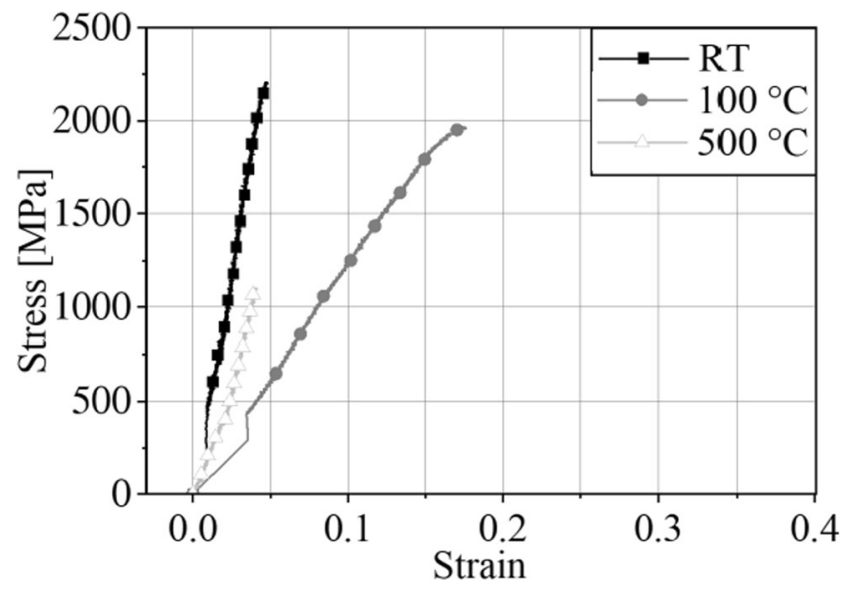

Fig. 11 Flow curves of the cemented carbide at different temperatures [23]

Figure 13 shows the summarized maximum residual stresses in the filler metal, cemented carbide, and steel for the different models. The positions of the maxima in the model are analogous to the positions of the maxima in Fig. 12. While the maximum distortion energy criterion (Von Mises) is particularly suitable for tough materials such as steel, the maximum normal stress theory was used for the analysis of the residual stresses in the cemented carbide, which is suitable for brittle materials. The results of the model show that the residual stresses in the steel considered here are uncritical. On the other hand, the internal stresses in the cemented carbide and in the filler metal represent a significant preloading of the joint. Figure 13 shows that the thickness of the brazing foils or the width of the brazing gap has an influence on the residual stresses. With thicker brazing foils, the residual stresses in the filler metal are reduced. The results for the brazing foils with $\mathrm{Cu}$-interlayer generally show a reduction of the residual stresses in the cemented carbide compared to the conventional brazing foils. When comparing the results for the models $\mathrm{C}$ and $\mathrm{D}$, a reduction of the residual stresses by $\Delta \sigma=100 \mathrm{MPa}$ or $15 \%$ can be seen. In contrast to the internal stresses in the cemented carbide, the internal stresses in the filler metal are higher in the case of the layered brazing foils than in the conventional brazing foils and only decrease with thicker layer brazing foils.

The results of the numerical calculations coincide with observations from reality. When using Ag 449-brazing foils on the cemented carbide, it is generally observed that failure occurs close to the filler metal, where the residual stress is concentrated. On the other hand, in the case of layered filler metals, the failure can be observed within the intermediate layer [9], where the material has the least strength and in addition the residual stress is concentrated. Since the results presented relate to an ideal, symmetrical, and smooth body. Stress increases that can be expected at component edges and in the area of the brazing gap have been neglected. Due to the relatively wide fine element grid, statements about the local stress distribution can only be made to a limited extent. 


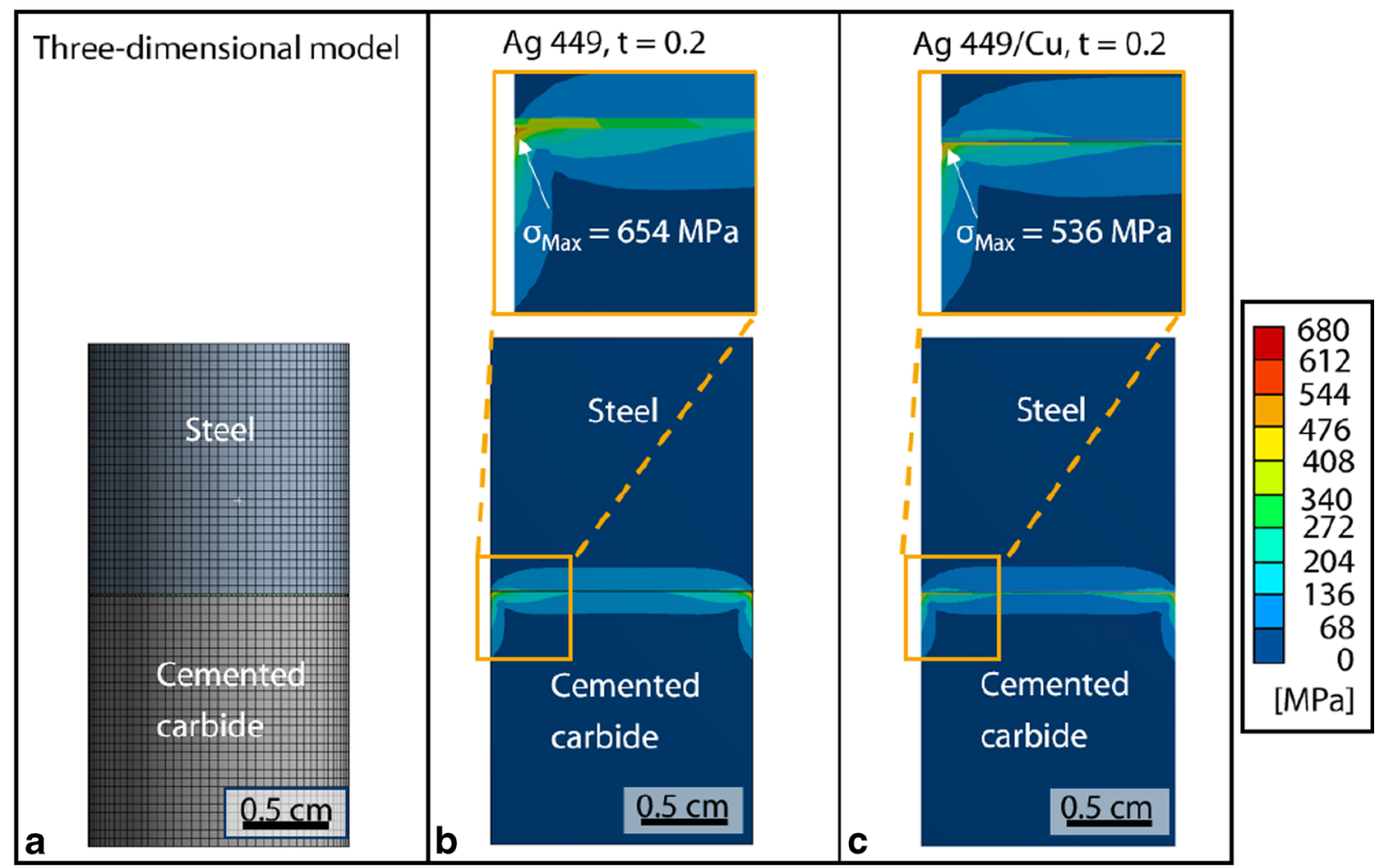

Fig. 12 Residual stress (Von Mises) in the brazing joint with Ag 449- and $\mathrm{Ag} 449 / \mathrm{Cu}$-brazing foil after cooling from $T_{1}=690{ }^{\circ} \mathrm{C}$ to $T_{2}=20{ }^{\circ} \mathrm{C}$

\section{Conclusions and outlook}

The results of the presented work show that it is possible to determine the condition of the filler metal by the use of additional force and displacement sensors, which indirectly allows a statement about the temperature in the core area of the brazing gap. The filler metal sags once it is completely in the molten state, which can be measured and used as an indicator of the core temperature. A further increase in temperature is no longer necessary from the time of sagging. Therefore, the brazing process is completed or a defined dwell time can be added to continue diffusion processes to a defined extent.

The process surveillance concept can be used in the future for more precise control of induction brazing processes. For this purpose, a "working time" can be defined as the "time at brazing temperature between the complete melting of the filler metal and the cooling". As a result, a process control that depends on the state of the filler metal can be realized, while remaining independent of geometry influences, etc. This filler metal state-based control can significantly reduce residual stresses, hard phase formation, and wetting errors.

A further reduction of residual stresses can be achieved by choosing the correct brazing foil. The numerical calculations of the residual stress states on cemented carbide/steel joints show the influence of the various common brazing foils and also different thicknesses of the filler metal or the brazing foil on the residual stress state. Thus, the calculations show that brazing foils with a $\mathrm{Cu}$-interlayer but also a thicker filler metal lead to a significant reduction of residual stress in the cemented carbide and thus reduce the mechanical preload.

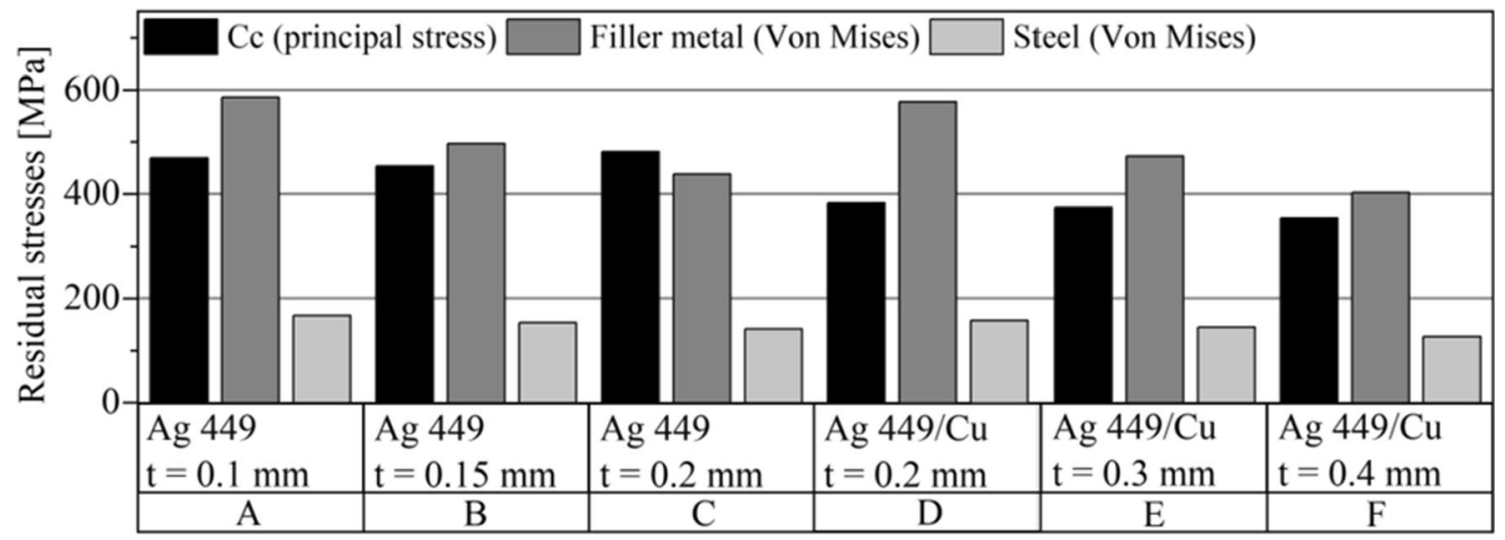

Fig. 13 Summarized results of the maximum residual stresses after cooling from $T_{1}=690{ }^{\circ} \mathrm{C}$ to $T_{2}=20{ }^{\circ} \mathrm{C}$ 
On the other hand, the use of these layered brazing foils leads to a residual stress concentration within the filler metal, which promotes failure within the $\mathrm{Cu}$-interlayer. In the future, further numerical calculations with an improved finite element grid are carried out on shear sample geometries. Among other things, the edge effects should also be included. In addition, a comparison of the numerical calculations with the failure behaviour of the samples in the shear test is intended.

In summary, monitoring of the condition of the filler metal, together with the use of suitable brazing foils, can improve the quality of cemented carbide/steel joints. In the next step, cemented carbide/steel shear specimens are produced with the new control concept and knowledge gained from the calculations. The results will be compared with samples produced using a conventional control system. It is expected that the new system can reduce variations in quality and strength without affecting the economics of the process.

Acknowledgments Open Access funding provided by Projekt DEAL. The IGF Project No. 19.201 N of the DVS (DVS-No. 07.083) was, on the basis of a resolution of the Lower House of the German Parliament, promoted by the German Ministry of Economic Affairs and Technology via AiF within the framework of the programme for the promotion of joint industrial research and development (IGF). The authors thank all the participants for the funding and the support. Many thanks also go to the project-accompanying committee for their constructive cooperation and the involved colleagues. Special thanks are due to the companies "SAXONIA Technical Materials GmbH" and "iew Induction Heating Systems GmbH" for the cooperation, the provision of equipment, and sample material as well as the many discussions and ideas. Many thanks also to the "DVS e.V." and the sponsors for the funding of the "DVS-IIW Young Professionals Program".

Open Access This article is licensed under a Creative Commons Attribution 4.0 International License, which permits use, sharing, adaptation, distribution and reproduction in any medium or format, as long as you give appropriate credit to the original author(s) and the source, provide a link to the Creative Commons licence, and indicate if changes were made. The images or other third party material in this article are included in the article's Creative Commons licence, unless indicated otherwise in a credit line to the material. If material is not included in the article's Creative Commons licence and your intended use is not permitted by statutory regulation or exceeds the permitted use, you will need to obtain permission directly from the copyright holder. To view a copy of this licence, visit http://creativecommons.org/licenses/by/4.0/.

\section{References}

1. Böhlke W (2002) Hartmetall - ein moderner Hochleistungswerkstoff. Mat-wiss u Werkstofftech 33(10):575-580

2. Ortner HM, Ettmayer P, Kolaska H (2014) The history of the technological progress of hardmetals. Int J Refract Met Hard Mater 44: 148-159

3. Aurich D (ed) (1999) Eigenspannungen und Verzug durch Wärmeeinwirkung. Forschungsbericht. Wiley-VCH, Weinheim

4. American Welding Society (1991) Brazing handbook. American Welding Society, Miami
5. Schimpfermann, M., and Schnee D. Löten in der Werkzeugindustrie https://www.saxonia-tm.de/Brazetec/de/Downloads/ Technisches\%20Know-How/index.html. Accessed 27 June 2019

6. August Rüggeberg GmbH \& Co. KG. 2019. Hartmetall Fräswerkzeuge. https://www.pferd.com/de-de/produkte/

7. Wirtgen Group. Funktionsprinzip Großfräsen. https://www.wirtgen.de/ de/technologien/anwendung/kaltfraesenfunktionsprinzip-grossfraesen/ fraesen-w-200-hi.php. Accessed 27 June 2019

8. LÖT. 2016. Brazing, high temperature brazing and diffusion bonding. LÖT 2016. DVS-Berichte Band 325. DVS Media $\mathrm{GmbH}$, Düsseldorf

9. LÖT 2019. Brazing, high temperature brazing and diffusion bonding - LÖT 2019. Lectures and posters of the 12th international conference taking place in Aachen on 21st to 23rd May 2019. DVS-Berichte

10. Boretius M, Kuntzmann B (2005) Löten und Härten im Vakuum zur Herstellung leistungsfähiger Gesteinwerkzeuge. Mat-wiss u Werkstofftech 36(8):377-380

11. Jiang C, Chen H, Wang Q, Li Y (2016) Effect of brazing temperature and holding time on joint properties of induction brazed WC-Co/carbon steel using Ag-based alloy. J Mater Process Technol 229:562-569

12. Ettmayer P, Suchentrunk R (1970) Über die thermische Stabilitt der Eta-Carbide. Monatshefte fr Chemie 101(4):1098-1103

13. Lugscheider E. 2002. Abschlussbericht: Hartlöten von hartmetallbestückten Bauteilen und Werkzeugen, Aif-Nr. 12.675 $\mathrm{N}$

14. K. Bobzin, M. Öte, S. Wiesner, J. Hebing. 2019. Improved process control during induction brazing - LÖT 2019

15. Saxonia Technical Materials GmbH. 2018. Technical Data Sheet BrazeTec 4900, Hanau

16. Saxonia Technical Materials GmbH. 2018. Technical Data Sheet BrazeTec 49/Cu, Hanau

17. Saxonia Technical Materials GmbH. 2018. Technical Data Sheet BrazeTec 7200, Hanau

18. Zhang J, Jin LY (2005) Numerical simulation of residual stress in brazing joint between cemented carbide and steel. Mater Sci Technol 21(12):1455-1459

19. Barrena MI, Gómez de Salazar JM, Gómez-Vacas M (2014) Numerical simulation and experimental analysis of vacuum brazing for steel/cermet. Ceram Int 40(7):10557-10563

20. Ottlik A, Schulze V, Pintschovius L, Müller H, Löhe D (2005) Analysis of residual stresses and distortions in brazed joints of cemented carbide and steel. MSF 490-491:491-496

21. K. Bobzin, W. Tillmann, T. Schläfer, A. Schlegel, A. M. Osmanda, S. Puidokas, L. Wojarski, and N. Kopp, Eds. 2009. Testing and prediction of mechanical properties of brazed joints. Proceedings of the 4th International Brazing and Soldering Conference, April 26-29, 2009, Hilton Walt Disney World Resort, Orlando, FL. AWS, Miami, Fla.

22. K. Bobzin and W. Tillmann. 2009. Abschlussbericht: Systematische Untersuchung der Fügeverbundeigenschaften von Lötungen mit $\mathrm{Ag}-, \mathrm{Cu}-$ und Ni-Basisloten mit anwendungsrelevanten Prüfverfahren (15.113N, DVS Nr. 7.006)

23. K. Bobzin and W. Tillmann. 2012. Abschlussbericht: Systematische Untersuchung der Eigenschaften gelöteter Fügeverbunde mit anwendungsrelevanten Prüfverfahren II (16.558 N / DVS-Nr. 7.062)

24. 2016. DIN 50106:2016-11: Prüfung metallischer Werkstoffe Druckversuch bei Raumtemperatur/Testing of metallic materials Compression test at room temperature. DIN Deutsches Institut für Normung e. V., Berlin, 50106

Publisher's note Springer Nature remains neutral with regard to jurisdictional claims in published maps and institutional affiliations. 